\title{
Eficácia de métodos de degermação cirúrgica: Uma revisão integrativa
}

\author{
Effectiveness of surgical degermation methods: An integrative review \\ Título eficacia de los métodos de dergermación quirúrgica: Uma revisión integrativa
}

\section{Resumo}

Objetivo: provocar uma reflexão acerca do saber dos profissionais de saúde em relação aos métodos de degermação. Metodologia: trata-se de uma Revisão Integrativa da Literatura, com abordagem qualitativa. A coleta de dados ocorreu entre o período de fevereiro a março de 2021, a partir de artigos contidos nos bancos de dados indexados na Biblioteca Virtual de Saúde e combinação dos Descritores em Ciências da Saúde: "Antissepsia"; "Desinfecção das Mãos" e "Higiene das Mãos", nos idiomas português, inglês e espanhol. O instrumento para organização do conteúdo foi um quadro contendo os autores, base de dados, revista de publicação, tipo de estudo e ano da publicação. Resultados: Foram selecionados 10 artigos, dentre as bases de dados: Base de Dados de Enfermagem, Literatura Latino-Americana e do Caribe em Ciências da Saúde e Medical Literature Analysis and Retrieval System Online. Conclusão: constatou-se através dos artigos que para evitar a proliferação de microrganismos devem ser adotadas a higienização adequada das mãos e adesão regular às boas práticas que são preconizadas. Também, foi possível identificar a dispensabilidade das escovas de degermação cirúrgica mediante estudos microbiológicos que demonstraram não haver mudança significativa com o uso desse artefato e sem ele. Ademais, é importante destacar como limitação do estudo a precariedade de artigos na área que abrangem a temática abordada, destacando a necessidade de implementação de novos estudos que atentem para a questão em foco.

Palavras-chave: Antissepsia; Desinfecção das mãos; Higiene das mãos. 


\begin{abstract}
Objective: to provoke a reflection on the knowledge of health professionals in relation to the methods of degermation. Methodology: this is an Integrative Literature Review, with a qualitative approach. Data collection took place between February and March 2021, based on articles contained in the databases indexed in the Virtual Health Library and the combination of Health Sciences Descriptors: "Antissepsia"; "Hand Disinfection" and "Hand Hygiene", in portuguese, english and spanish. The instrument for organizing the content was a table containing the authors, database, magazine of publication, type of study and year of publication. Results: 10 articles were selected from the databases: Base de Dados de Enfermagem, Literatura Latino-Americana e do Caribe em Ciências da Saúde and Medical Literature Analysis and Retrieval System On-line. Conclusion: it was found through the articles that to avoid the proliferation of microorganisms, adequate hand hygiene and regular adherence to the good practices that are recommended must be adopted. Also, it was possible to identify the dispensability of surgical cleaning brushes through microbiological studies that demonstrated that there was no significant change with the use of this artifact and without it. In addition, it is important to highlight, as a limitation of the study, the precariousness of articles in the area that cover the topic addressed, highlighting the need to implement new studies that address the issue in focus.
\end{abstract}

Keywords: Antisepsis; Hand disinfection; Hand hygiene.

\title{
Resumen
}

Objetivo: provocar una reflexión sobre el conocimiento de los profesionales de la salud en relación a los métodos de desgermación. Metodología: se trata de una Revisión de Literatura Integrativa, con enfoque cualitativo. La recolección de datos se realizó entre febrero y marzo de 2021, a partir de artículos contenidos en las bases de datos indexadas en la Biblioteca Virtual em Saúde y la combinación de Descriptores en Ciencias de la Salud: "Antisepsia"; "Desinfección de las Manos" e "Higiene de Manos", en portugués, inglés y español. El instrumento para la organización del contenido fue una tabla con autores, base de datos, revista de publicación, tipo de estudio y año de publicación. Resultados: se seleccionaron 10 artículos de las bases de datos: Base de Dados de Enfermagem, Literatura Latino-Americana e do Caribe em Ciências da Saúde y Medical Literature Analysis and Retrieval System Online. Conclusión: se constató a través de los artículos que para evitar la proliferación de microorganismos, se debe adoptar una adecuada higiene de manos y el cumplimiento regular de las buenas prácticas que se recomiendan. Asimismo, fue posible identificar la dispensabilidad de los cepillos de limpieza quirúrgica a través de estudios microbiológicos que demostraron que no hubo cambios significativos con el uso de este artefacto y sin él. Además, es importante resaltar, como limitación del estudio, la precariedad de los artículos en el área que cubren el tema abordado, destacando la necesidad de implementar nuevos estudios que aborden el tema en foco.

Palabras clave: Antisepsia; Desinfección de las manos; Higiene de manos.

\section{Introdução}

As infecções relacionadas à assistência em saúde são importantes eventos adversos aos quais os pacientes estão expostos, representando relevantes indicadores de qualidade à assistência prestada (Dutra et al., 2015).

Em relação às infecções, destaca-se as Infecções do Sítio Cirúrgico (ISC), que são avaliadas como episódios adversos que ocorrem frequentemente e refletem como uma ameaça à segurança do paciente, podendo ser decorrente da assistência prestada e podendo resultar em dano físico, social e/ou psicológico do indivíduo (Brasil, 2017).

Portanto, a prática de higienização das mãos é, desde o século XIX, reconhecida como importante medida preventiva das ISC no momento perioperatório, uma vez que promove o cuidado cirúrgico ao paciente e reduz a quantidade de microrganismos presentes nas mãos dos profissionais envolvidos no ato cirúrgico (Dutra et al., 2015; Kawagoe, 2016).

Neste ínterim, as mãos contêm dois tipos particulares de microrganismos: os pertencentes à microbiota residente e os que abrigam a microbiota transitória. A microbiota residente é formada geralmente por microorganismos de baixa virulência que integram as camadas mais profundas da pele e que são de difícil remoção quando a higienização ocorre apenas com água e sabão. A microbiota transitória, por sua vez, é geralmente adquirida pelo contato direto com o paciente e equipamentos contaminados e apresenta melhor resultado de remoção com água e sabão através de fricção mecânica, uma vez que coloniza as camadas mais superficiais da pele (Dotto et al., 2015).

Para a eliminação da microbiota transitória e redução da microbiota residente, destaca-se a degermação, através de processo químico-mecânico, realizado no período pré-operatório por meio de substâncias antissépticas com poder antimicrobiano prolongado (Oliveira \& Gama, 2016). 
Ademais, para que haja a redução e eliminação das microbiotas, é necessário a utilização da antissepsia cirúrgica que é definida por Oliveira e Gama (2016), como um método pré-operatório de atividade antimicrobiana feito a partir de produtos antissépticos a base de Polivinilpirrolidona Iodo (PVPI) ou Gluconato de Clorexidina (CHG), ou ainda fricção com preparação alcoólica (PA), que tem o intuito de eliminar os microorganismos da microbiota transitória e diminuir os microrganismos da microbiota residente. Sendo sua eficácia dependente de vários requisitos: antisséptico utilizado, tempo de duração, tempo de aplicação, não uso de acessórios, cuidados com as unhas.

É de grande relevância apontar o papel do enfermeiro no que diz respeito ao controle e prevenção de infecções, observando a importância deste profissional na assistência prestada diariamente ao paciente e cujas ações e atitudes interferem direta e completamente no bem-estar do paciente (Giroti \& Garanhani, 2015).

Assim, salienta-se a importância desse estudo, visto que há a necessidade de pesquisas que considerem os passos da degermação e suas possíveis falhas, de modo que possa sensibilizar profissionais de saúde, acadêmicos e docentes sobre a importância dessa temática e do encorajamento para modificar práticas ineficientes dentro do serviço de saúde. Com isso, a pesquisa tem a intenção de provocar uma reflexão acerca do saber dos profissionais de saúde em relação aos métodos de degermação com o uso de escovas e artefatos.

Diante do exposto, surge a seguinte questão norteadora: Qual a eficácia dos métodos de degermação utilizados pela equipe de saúde?

\section{Metodologia}

Este estudo trata-se de uma Revisão Integrativa da Literatura (RIL), com abordagem qualitativa. Lanzoni e Meirelles (2011) definem bem aspectos relevantes e importantes para a realização da pesquisa desde o início, como a coleta de dados e a análise dos resultados, sistematizando-os e abrangendo determinados assuntos a partir de outros estudos. Tendo como finalidade reunir, sintetizar e resumir o conhecimento científico já existente, de forma que permita avaliar e comparar as publicações científicas sobre a referida temática (Bublitz et al., 2012).

Para Mendes, Silveira e Galvão (2008), a elaboração da revisão integrativa inicia-se com a definição de um problema e a formulação de uma hipótese ou questão de pesquisa que apresente relevância para a saúde.

A coleta de dados ocorreu entre o período de Fevereiro a Março de 2021, a partir de artigos contidos nos bancos de dados indexados na Biblioteca Virtual de Saúde (BVS), através da combinação de Descritores em Ciências da Saúde (DECS). Os descritores utilizados foram "Antissepsia"; "Desinfecção das Mãos" e "Higiene das Mãos", nos idiomas português, inglês e espanhol, com a utilização do descritor Bowleano AND.

O fluxo obtido de artigos será demonstrado no fluxograma da Figura 1. 
Research, Society and Development, v. 10, n. 8, e23810817292, 2021

(CC BY 4.0) | ISSN 2525-3409 | DOI: http://dx.doi.org/10.33448/rsd-v10i8.17292

Figura 1. Fluxograma de seleção dos artigos. Campina Grande,PB, Brasil,2021.

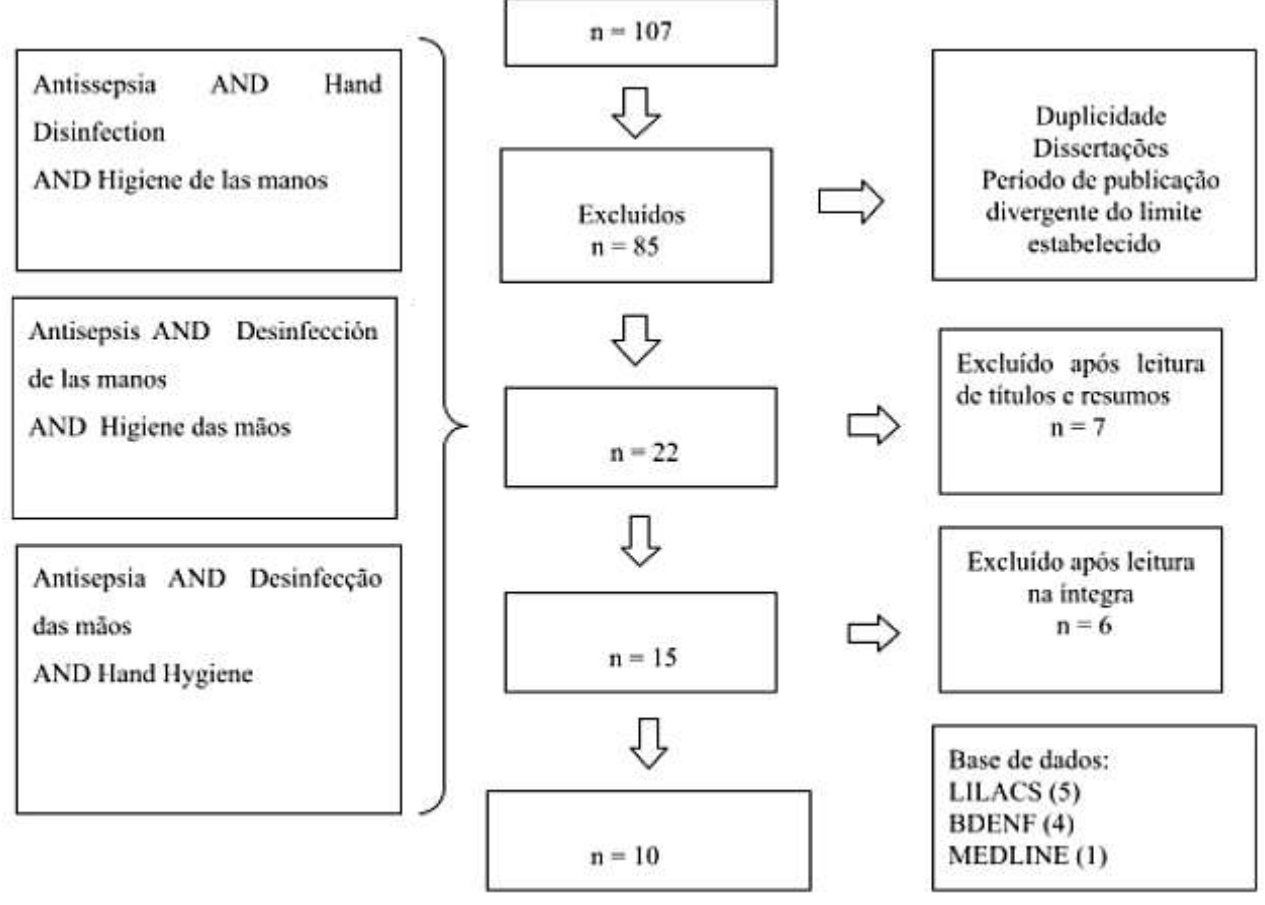

Fonte: Dados da Pesquisa.

Para subsidiar o trabalho, foram utilizados os seguintes critérios de inclusão: ter sido publicado nos últimos cinco anos (2015-2021), nos idiomas referidos anteriormente e disponibilizados na íntegra. Foram excluídos da pesquisa estudos que apresentaram duplicidade, teses e dissertações, resultando em uma amostra de 10 artigos.

\section{Resultados e Discussão}

Os dados serão apresentados em forma de tabela, identificando os resultados relevantes de acordo com a referida temática. 
Tabela 1. Demonstrativo dos artigos de acordo com autor, base de dados, revista de publicação, tipo de estudo e ano de publicação, Campina Grande, PB, 2021. ( $\mathrm{n}=10$ ).

\begin{tabular}{|c|c|c|c|}
\hline Autor e Ano de Publicação & Base de dados & Revista de publicação & Tipo de Estudo \\
\hline $\begin{array}{l}\text { Assis; Araújo; Lopes. } \\
2020\end{array}$ & LILACS & Rev. Associação Brasileira Médica & Revisão da literatura \\
\hline $\begin{array}{l}\text { Paula, et.al. } \\
\quad 2020\end{array}$ & BDENF & Rev. Brasileira de Enfermagem & Transversal \\
\hline $\begin{array}{l}\text { Peixoto et.al. } \\
2020\end{array}$ & BDENF & Revista SOBECC & Transversal, de prevalência \\
\hline $\begin{array}{l}\text { Shimoya-Bittencourt, et.al. } \\
2019\end{array}$ & LILCAS & Rev. Fisioterapia & Experimental \\
\hline $\begin{array}{c}\text { Menezes, et.al. } \\
2016\end{array}$ & LILACS & Rev de Epidemiologia e controle de infecção & Transversal \\
\hline $\begin{array}{l}\text { Rosado \& Silva. } \\
2016\end{array}$ & LILACS & Rev. Saúde em foco & Experimental \\
\hline $\begin{array}{c}\text { Silveira, et.al. } \\
2016\end{array}$ & MEDLINE & The Canadian Veterinary Journal & Ensaio clínico randomizado \\
\hline $\begin{array}{c}\text { Urquiza, et.al. } \\
2016\end{array}$ & BDENF & Rev. Interdisciplinar & Experimental \\
\hline $\begin{array}{c}\text { Almeida, et.al. } \\
2016\end{array}$ & BDENF & Rev. Bahiana de Saúde Pública & Experimental \\
\hline $\begin{array}{l}\text { Dotto et.al. } \\
\quad 2015\end{array}$ & LILCAS & Rev. de Cirurgia e Traumatologia Buco-maxilo-facial & Ensaio clínico randomizado \\
\hline
\end{tabular}

Fonte: Autores.

Em relação à tabela, percebe-se que a maioria das publicações ocorreram no ano de 2016, na base de dados LILACS, correspondendo à 50\% (5), seguido da BNDENF com 40\% (4) e MedLine com 10\% (1), porém, nota-se que os artigos selecionados se encontram indexados em bases de dados internacionais, possuindo originalidade nacional.

Os estudos analisados identificaram os métodos de degermação de uma forma eficaz, em uma nova perspectiva para prática profissional, tendo como finalidade disseminar o conhecimento aos profissionais de saúde, especificamente, aos enfermeiros.

De acordo com Almeida et al. (2016), a lavagem apropriada das mãos, após exposição a qualquer possível contágio nas atitudes do cotidiano, é uma atitude importante na eliminação de micróbios exógenos que possibilitam a infecção de pessoas ou a contaminação de objetos com os quais venham a ter contato.

Foram observados que os fatores referentes à carga de trabalho, ao estresse, à realização de atividades com alto risco de transmissão cruzada de patógenos, à falta de conhecimento sobre o protocolo de higienização das mãos, à falta de exemplo positivo de seus superiores, à maus hábitos, à simples esquecimento, à irritação e ao ressecamento da pele causado pelo uso sucessivo de produtos foram apontados como as principais causas para o não cumprimento da técnica adequada (Ezaias et al., 2016).

Corroborando com o estudo anterior, a OMS aponta diversos fatores como primordiais como resposta para a baixa adesão dos profissionais de saúde à higienização das mãos, como: irritação e ressecamento de pele e problemas dermatológicos. Assim, é de grande relevância inferir que profissionais de saúde com problemas dermatológicos apresentam altas taxas de 
colonização das mãos por microrganismos, tais como S. aureus multirresistente, podendo ser fonte de uma infecção (World Health Organization, 2014).

Portanto, o procedimento de higienização das mãos torna-se inadequado na prática diária por não haver o desenvolvimento correto, tornando o procedimento ineficaz pela falta de habilidades técnicas por parte dos profissionais de saúde, preocupados apenas com a quantidade e não com a qualidade deste ato.

Segundo Colares (2015), a atividade microbicida da clorexidina ocorre principalmente contra bactérias gram-positivas e gram-negativas. Não atua nas formas esporulantes, exceto em altas temperaturas. Alguns vírus lipofílicos, como influenza, vírus do herpes e HIV são rapidamente inativados.

O álcool 70\% foi estatisticamente eficaz na redução de crescimento de microrganismos em relação à lavagem simples das mãos. O álcool em forma de gel demonstrou ter melhor resultado quando aplicado sem a lavagem prévia das mãos, enquanto que o álcool na forma líquida foi mais eficaz após a lavagem das mãos (Shimoya-Bittencourt et al., 2019).

Logo, a partir da afirmação acima, Rosado e Silva (2016) observaram a eficácia da clorexidina 2\%, que alcançou percentuais de redução $100 \%$ eficazes, sendo o mais eficiente, seguido do álcool em gel (93,80\% de redução das Unidades Formadoras de Colônias), álcool a 70\% (80,99\%) e água com sabão triclosan (70,59\%). Assim, os grupos submetidos ao tratamento com esses antissépticos apresentaram significativa redução das Unidades Formadoras de Colônias (UFC's) de microorganismos. Dessa forma, ele aponta que não há eficácia adicional quando comparada à fricção das mãos, apenas à friç̧ão com presença de escova ou artefato.

O estudo realizado com 33 profissionais de saúde, observou que das 18 amostras, apenas 5 apresentaram contaminação após a higienização das mãos com solução alcoólica. Já das 15 amostras que utilizaram a escova de digliconato de clorexidina 2\%, 12 apresentaram contaminação após a antissepsia pré-operatória, sendo a solução antisséptica alcoólica mais eficaz se comparada à técnica tradicional de escovação com digliconato de clorexidina a 2\% (Menezes et al., 2016).

Segundo o autor supracitado a técnica com uso de escova e a fricção das mãos apontam resultados sem diferenças consideráveis, indicando que, para que a técnica de escovação seja realmente eficaz, é necessário que seja realizada corretamente e no tempo adequado, visto que a fricção dispensa esse tempo gasto na escovação e que o grande potencial de redução microbiana está relacionado ao antisséptico utilizado. Entretanto, a realidade observada em alguns estudos, é que há, principalmente, a adesão insuficiente da equipe cirúrgica quanto ao tempo e técnica para a execução desse procedimento (Oliveira \& Gama, 2016).

Para Kawagoe (2016), nas últimas décadas, houve grandes mudanças quanto ao tipo de produto antisséptico utilizado na degermação cirúrgica das mãos, favorecendo o uso de preparação alcoólica (PA), sem o uso de água e escova, representando custo-efetividade e sustentabilidade ecológica quando comparada aos procedimentos tradicionais como a degermação cirúrgica das mãos com Polivinilpirrolidona Iodo (PVPI) ou Gluconato de Clorexedina (CHG).

De fato, em estudo de campo, observou-se a redução microbiana após antissepsia cirúrgica das mãos, realizada com preparação alcoólica, em diferentes tempos, onde as técnicas realizadas em menos de 90 segundos, houveram $80 \%$ de redução severa (acima de 80\%), 6,7\% de redução moderada (entre 51 e 80\%) e 13,3\% de redução leve (até 50\%). Nas técnicas desempenhadas em mais de 180 segundos, todas as amostras apresentaram redução de contagem bacteriana, o que não ocorreu em tempos menores de antissepsia, concluindo-se que quando a técnica e o tempo recomendados são seguidos, maior é a redução bacteriana, em comparação aos tempos menores (Peixoto et al., 2020).

Dessa maneira, Dotto et al. (2015) apontam que o uso de escova para higienização das mãos não oferece descontaminação adicional, uma vez que essa técnica é comprometida devido ao desconforto mecânico gerado com o uso desse artefato, induzindo o profissional da saúde a diminuir o tempo de escovação e, consequentemente, de higienização das mãos. Outro fator a ser considerado é que o uso de artefato não aumenta a eficácia da redução microbiana, não havendo semelhança significativa entre os resultados das duas técnicas. 
Os autores supracitados apontam que a redução bacteriana foi semelhante nas duas técnicas de degermação: fricção com sabonete contendo clorexidina a $2 \%$ e degermação com escova impregnada com clorexidina a $2 \%$, confirmando que o ato de friccionar as mãos e antebraços com sabonete contendo antisséptico permite um método de degermação pré-cirúrgico das mãos mais rápido, mais barato e eficaz na redução de microrganismos transitórios e residentes da pele.

Já o uso de PVPI a 10\% e clorexidina, quando comparados, demonstraram resultados satisfatórios, uma vez que comprovou que o uso de artefatos como escova não aponta efeito adicional nos resultados da antissepsia. Mostrou ainda, que as substâncias antissépticas utilizadas colaboraram para redução bacteriana. Dessa forma, o estudo aponta que a realização criteriosa e correta da antissepsia pré-operatória das mãos é mais relevante que a escolha da técnica e do antisséptico (Urquiza, Anjos \& Ribeiro, 2016).

No entanto, Silveira et al. (2016) relatam que a técnica de lavagem tradicional das mãos utilizando gluconato de clorexidina a 4\% e água não apresentou diferença significativa na média de UFC's quando comparadas. Relatam ainda que a lavagem das mãos com sabão neutro reduz a contagem de UFC em 7,5 vezes. Ademais, a fricção das mãos com clorexidina a $1 \%$ foi eficaz para a desinfecção das mãos, removendo a necessidade de esfregaços tradicionais com escovas. É ainda importante salientar que, apesar do alto avanço tecnológico, as taxas de perfuração de luvas continuam sendo significativas, inferindo e dando maior importância ao cuidado durante a antissepsia pré-cirúrgica das mãos.

O estudo de Kampf et al. (2020) relata que as soluções de etanol (78-95\%), 2-propranolol 45\%, em combinação com 1-propanolol 30\%, glutaraldeído (0,5-2,5\%), formaldeído (0,7 -1\%) e iodopovidona (0,23-7,5\%) foram os agentes mais eficazes para antissepsia, com redução da carga viral de $4 \log _{10}$ ou mais, ou seja, acima do valor recomendado pelas autoridades americanas e europeias. Dados bastante relevantes para a nova realidade pandêmica do COVID-19.

Em uma análise quantitativa realizada durante a pandemia, foi observado que a "equipe de enfermagem", quando comparada com a "equipe médica", higieniza suas mãos 39,44\% mais vezes, enquanto que outros profissionais, possuem chance 30,62\% menor de realizar a higiene de forma adequada quando comparada a "equipe da enfermagem". Outra análise importante observada neste artigo foi em relação aos momentos de higienização das mãos, onde foi observado que os profissionais lavam 4,5 vezes mais as mãos antes do contato com o paciente do que após, corroborando com a cultura do uso de luvas como barreiras de proteção, predispondo a não realização da higienização das mãos (Paula et al., 2020).

Sob outra perspectiva referente a pandemia, o estudo de Assis, Araújo e Lopes (2020), relata a ineficiência da clorexidina para a desinfecção de superfícies, como plástico, protetores faciais, luvas de látex, máscaras e aventais descartáveis. Os dados revelam uma preocupação quanto à disseminação do novo coronavírus entre os profissionais de saúde, uma vez que a clorexidina é amplamente utilizada em procedimentos cirúrgicos e invasivos. Portanto, recomenda-se o uso de outros desinfetantes, entre eles álcool 70\%, hipoclorito de sódio $0,1 \%$, lixívia contendo hipoclorito (sódio ou cálcio) $0,1 \%$ ou iodopovidona $1 \%$, que se mostraram mais eficazes.

Sendo assim, fica claro que a simples higienização da maneira correta é o meio mais eficaz de controle, evidenciando que não há necessidade de utilização de artefatos para aumento do controle de microorganismos (Rosado \& Silva, 2016).

\section{Considerações Finais}

Ressalta-se que os objetivos traçados neste presente estudo foram alcançados de forma eficaz, sendo de grande relevância para o meio acadêmico pois permite o aprofundamento e aperfeiçoamento sobre o tema proposto.

Constatou-se através dos estudos que, para evitar a proliferação de microrganismos devem ser adotadas duas medidas eficazes: a higienização adequada das mãos, com uso de produtos e técnicas adequadas e adesão regular às boas práticas que são preconizadas. Para essa mudança de prática, são necessários programas de educação permanente, capacitação e novas pesquisas científicas. 
Além disso, foi possível identificar que todos partem de um mesmo pressuposto: a dispensabilidade das escovas de degermação cirúrgica mediante estudos microbiológicos que demonstraram não haver mudança significativa com o uso desse artefato ou sem ele. Um fator prévio que prevaleceu nos artigos foi o risco de lesões causadas pelas escovas, que são apontados como fatores preponderantes para que a adesão à essa prática seja baixa entre os profissionais de saúde.

Portanto, considerando a grande vulnerabilidade tanto por parte dos profissionais da área da saúde quanto dos pacientes, no que diz respeito à infecção cruzada, é indispensável o uso de ações que garantam um atendimento mais seguro, como o cuidado com a HM, a degermação e todos o procedimentos que possam colocar em risco a vida do paciente, utilizando os degermantes de forma correta e com o tempo preconizado.

Tendo em vista tudo o que foi apresentado, este trabalho irá contribuir para o respaldo científico da temática abordada, sendo recomendado, então, novas pesquisas de campo, bem como laboratoriais, com metodologias rigorosas e de alta credibilidade científica, para que o assunto seja destrinchado e esmiuçado apropriadamente.

\section{Referências}

Almeida, R. M., Santos, T. C., Palasson, R. R., Cabral, M. C., \& Liberto, M. I. M. (2016). Higienização das mãos: questão de educação, saúde e cidadania. Revista Baiana de Saúde Pública, 40(1).

Assis, M. S. D., Araújo, R.A.D.A.M., \& Lopes, A. M. M. (2020). Safety alert for hospital environments and health professional: chlorhexidine is ineffective for coronavirus. Revista da Associação Médica Brasileira, 66, 124-129.

BRASIL. Agência Nacional de Vigilância Sanitária. Medidas de Prevenção de Infecção Relacionada à Assistência à Saúde. 145.

Bublitz, S., de Azevedo Guido, L., de Oliveira Freitas, E., \& Lopes, L.F.D. (2012). Estresse em estudantes de enfermagem: uma revisão integrativa. Revista de Enfermagem da UFSM, 2(3), 530-538.

Colares, A. N. G. E. L. I. T. A. (2015). Clorexidine indicação para uso em serviços de saúde. São Paulo: Faculdade Método de São Paulo. Disponível em: https://www.ccih.med.br/wp-content/uploads/2015/08/angelita-colares.pdf

Dotto, P. P., Zucuni, C. P., Antes, G. B., Fernandes, M., Favarin, A. G., Christ, R., \& Barboza, V. D. S. (2015). Eficácia de dois métodos de degermação das mãos. Revista de Cirurgia e Traumatologia Buco-maxilo-facial, 15(3), 07-14.

Dutra, G. G., da Costa, M. P., Bosenbecker, E. O., de Lima, L. M., de Siqueira, H. C. H., \& Cecagno, D. (2015). Nosocomial infection control: role of the nurse. Revista de Pesquisa: Cuidado é Fundamental Online, 7(1), 2159-2168.

Ezaias, G. M., Watanabe, E., Megumi, N. S. C., Tojeiro Giordani, A., Megumi Sonobe, H., \& de Andrade, D. (2016). Skin Tolerance To Alcohol-Based Preparations: Basis For Improvement Of Hand Hygiene Practices. Journal of Nursing UFPE/Revista de Enfermagem UFPE, 10(8).

Giroti, S.K.O., \& Garanhani, M. L. (2015). Infecções relacionadas à assistência à saúde na formação do enfermeiro. Revista da Rede de Enfermagem do Nordeste, 16(1), 64-71.

Kampf, G., Todt, D., Pfaender, S., \& Steinmann, E. (2020). Persistence of coronaviruses on inanimate surfaces and their inactivation with biocidal agents. Journal of hospital infection, 104(3), 246-251.

Kawagoe, J. Y. (2016). Tendências e desafios do preparo cirúrgico das mãos. Rev. SOBECC, 217-222.

Lazoni, G. M. M., Meirelles, B. H. S. (2011) Liderança do enfermeiro: uma revisão integrativa da literatura. Rev. Latino-Am. Enfermagem maio-jun;19(3).

Menezes, R. M., Cardoso, V., Hoehr, C. F., Bulle, D., Burgos, M. S., Benitez, L. B., \& Renner, J. D. P. (2016). Avaliação microbiológica da antissepsia préoperatória das mãos de profissionais de enfermagem de um centro cirúrgico. Revista de Epidemiologia e Controle de Infecção, 1(1), $178-191$.

Oliveira, A. C. D., \& Gama, C. S. (2016). Antissepsia cirúrgica e utilização de luvas cirúrgicas como potenciais fatores de risco para contaminação transoperatória. Escola Anna Nery, 20(2), 370-377.

Paula, D. G. D., Francisco, M. R., Freitas, J. D., Levachof, R. C. Q., Fonseca, B. D. O., Simões, B. F. T., \& Bilio, R. D. L. (2020). Higiene das mãos em setores de alta complexidade como elemento integrador no combate do Sars-CoV-2. Revista Brasileira de Enfermagem, 73.

Peixoto, J. G. P., Branco, A., Dias, C. A. G., Millão, L. F., \& Caregnato, R. C. A. (2020). Antissepsia cirúrgica das mãos com preparação alcoólica: redução microbiana em diferentes tempos de uso no centro cirúrgico. Rev. SOBECC, 83-89.

Pereira, L.J., Murata, R. M., Pardi, V., \& Mattos, F. F. (2021). Streamlining the dental care during COVID-19 pandemic: updated clinical recommendations and infection control management framework. Brazilian Oral Research, 35.

Rosado, A. V., \& Silva, F. L. (2016). A Avaliação Da Eficácia De Antissépticos Nas Mãos Dos Profissionais De Saúde/Evaluating The Effectiveness Of Antiseptics In The Hands Of Health Professionals. Saúde em Foco, 3(1), 01-19. 
Research, Society and Development, v. 10, n. 8, e23810817292, 2021

(CC BY 4.0) | ISSN 2525-3409 | DOI: http://dx.doi.org/10.33448/rsd-v10i8.17292

Silveira, E. A., Bubeck, K. A., Batista, E. R., Piat, P., Laverty, S., Beauchamp, G., \& Elce, Y. (2016). Comparison of an alcohol-based hand rub and water-based chlorhexidine gluconate scrub technique for hand antisepsis prior to elective surgery in horses. The Canadian Veterinary Journal, $57(2), 164$.

Shimoya-Bittencourt, W., Santos, V. M., dos Santos, D. C., Zdziarski, E. S., Lima, M. F., Frederico, R. C. P., \& de Paula, C. C. (2019). Higienização simples e o uso do álcool 70\% no controle de microrganismos das mãos em universitários da área da saúde. Fisioterapia Brasil, 20(3), 376-383.

Urquiza, M. de C., dos Anjos, A. D. S., Ribeiro, A. C. B., da Costa Borba, M. S., de Carvalho Filho, D. U., \& Lago, E. C. (2016). Comparação da eficácia e efeito residual de duas técnicas de antissepsia pré-operatória das mãos com duas substâncias antissépticas. Revista Interdisciplinar, 9(3), 112-120

World Health Organization. (2005). WHO guidelines on hand hygiene in health care (advanced draft): a summary: clean hands are safer hands (No. WHO/EIP/SPO/QPS/05.2). World Health Organization. http://www.who.int/patientsafety/events/05/HH_en.pdf 